\title{
Inclusive Cities: The New Issue in Urban Development
}

\author{
Rini Rachmawati \\ Urban Development Research Group \\ Department of Development Geography \\ Faculty of Geography \\ Universitas Gadjah Mada \\ Coressponding email: r_rachmawati@geo.ugm.ac.id
}

\begin{abstract}
Currently, the city development is expected to include aspects of inclusiveness. Inclusiveness in urban development is an attempt to include and involve marginalized people i.e. people with disabilities, women, the elderly, children, poor people. One of the important issues discussed in The Third Preparatory Committee Meeting for Habitat III (PrepCom 3 Habitat III) in Surabaya is that countries around the world are expected to work together in addressing increasingly complex urban problems. Future city is expected to be a more comfortable environment and a center of civilization. The development plan has to include the issues of the inclusive city. In connection with the Habitat Program as part of the Sustainable Development Goals (SDG's) number 11, urban management must ensure sustainable city and communities in order to open up and be inclusive to accommodate everyone who wants to get into it. This paper will further discuss the study of inclusive cities in the document of the new urban agenda as a result of Habitat III in Quito, compliment with the result of the discussion on inclusive cities in preparing PrepCom 3 Habitat III event, also the implementation of the inclusive city in development in Yogyakarta City.
\end{abstract}

\section{Keywords -Inclusive cities, urban development}

\section{INTRODUCTION}

The new sustainable development goals have been echoed in order to be achieved in 2030. One goal is to "make cities and human settlements inclusive, safe, resilient and sustainable". It reflects growing recognition that human development depends on how well urbanization is managed. This is important for Indonesia, where the urbanization rate is very high. In 2016, the number of Indonesian people living in cities is estimated to be $54 \%$ of the whole population. If the Indonesian population is currently more than 240 million people, it means there are at least 129.6 million people making cities densely populated. This number shows a very high increase compared to the one based on the result of the 2010 population census. In that time, $49.8 \%$ of the Indonesian population, 237.6 million people, lived in cities.

The existence of a city cannot be separated from humans. Therefore, the development of the city should be inclusive for all segments of society. However, the poor have so far been still marginalized and neglected in the process of development in big cities in Asia Pacific, including Indonesia. Today the concept of inclusive urban development is becoming an issue. In the international scope, the discussion on inclusive urban development has been written about meetings or conferences related to the one on new urban agenda. Inclusive development is the one involving marginalized groups, such as gender (women, the elderly and children), the poor, and the disabled. So far there have been weaknesses and shortcomings in urban development in terms of accommodating those marginalized groups.

The concept of inclusive development stresses on social and ecological aspects and political dimension of development in which inclusive social is more prominent than ecological aspects so that the implementation are focusing more on social inclusiveness (Gupta and Vegelin, 2016). The social inclusiveness aims at empowering the poorest through investing in human capital and enhancing the opportunities for participation (Gupta and Vegelin, 2016). The environmental inclusiveness is related to how the poor earn their living depending on local ecosystem, how the susceptibility of the poor can be made worse by climatic change and how much they demand for limited sources of land, water, and others (Zoomers 2010; Fairhead et al.2012; Leach et al. 2012; Chambers and Conway 1991; Paavola and Adger 2006 in Gupta and Vegelin (2016).

Through the study of new urban agenda, it can be found out whether urban development has been committed to accommodating the marginalized groups by taking inclusive urban development into priority. Indonesia, particularly Surabaya, has been appointed to host the session for The Third Preparatory Committee Meeting for Habitat III (PrepCom 3 Habitat III). In the preparation for Prep.Com 3 habitat III, the discussion on inclusive urban development has been implemented in Yogyakarta. Meanwhile, in the draft of new urban agenda as well as the agenda that has been agreed in the session of Habitat III in Quito, several points related to inclusive 
urban development mainly from the aspects of infrastructure provision and basic needs have been written about. The basic needs include the ones for housing and others for inclusive groups. This paper will further discuss the study of inclusive urban development in the document of the new urban agenda, the result of the discussion on inclusive cities, as well as one of the examples of implementing inclusive urban development in Yogyakarta.

\section{METHOD}

This paper is based on a review of the results of a focus group discussion on the theme of Cities Inclusive. The Focus Discussion is followed by the relevant stakeholders, including from the government at national and local level, academics, youth representatives, NGO and others. In addition, this paper was developed through a review of documents related to the Urban Agenda.

\section{A. The New Urban Agenda}

\section{FINDING AND DISCUSSION}

The discussion on the new urban agenda has been implemented in several stages; among others are 1) Zero Drafts of the New Urban Agenda that was submitted on 6 May 2016 by the Bureau of the Preparatory Committee for discussion at the informal intergovernmental negotiations and informal hearings with local authorities associations and civil society organizations in May and June, in New York, USA, 2) The Draft New Urban Agenda that was prepared on July 18, 2016 in New York, USA on the basis of inputs and negotiations throughout the Habitat III intercessional process leading to, and, 3) Surabaya Draft of the New Urban Agenda. This draft is the result of the negotiations at the third session of the Preparatory Committee for the Habitat III Conference (PrepCom3), held in Surabaya, Indonesia, 25-27 July 2016.

The new urban agenda is closely related to the achievement of Sustainable Development Goals, mainly related to SDGs No. 11, i.e. Sustainable Cities and Communities.

The New Urban Agenda contributes to the implementation and localization of the 2030 Agenda for Sustainable Development in an integrated manner, and to the achievement of the Sustainable Development Goals (SDGs) and targets, including SDG 11 of making cities and human settlements inclusive, safe, resilient, and sustainable. Achieve gender equality and empower all women and girls, ensuring women's full and effective participation and equal rights in all fields and in leadership at all levels of decision making, and by ensuring decent work and equal pay for equal work, or work of equal value for all women, as well as preventing and eliminating all forms of discrimination, violence, and harassment against women and girls in private and public spaces. (Habitat III New Urban Agenda, Draft Outcome Document for Adoption in Quito, October 2016, 10 September 2016).
The United Nations Conference on Housing and Sustainable Urban Development (Habitat III) was held between October 17 and 20, 2016 in Quito, Ecuador. The main issue is about rapid urbanization. Because of this issue, the need for houses and their environment to live in has been the basic need that should also accommodate certain groups of people, like the poor, the elderly, children, women, the disabled etc.

By 2050 the world urban population is expected to nearly double, making urbanization one of the $21^{\text {st }}$ century's most transformative trends. As the population, economic activities, social and cultural interactions, as well as environmental and humanitarian impacts, are increasingly concentrated in cities, this poses massive sustainability challenges in terms of housing, infrastructure, basic services, food security, health, education, decent jobs, safety and natural resources, among others. By readdressing the way cities and human settlements are planned, designed, financed, developed, governed, and managed, the New Urban Agenda will help to end poverty and hunger in all its forms and dimensions, reduce inequalities, promote sustained, inclusive, and sustainable economic growth, achieve gender equality and the empowerment of all women and girls, in order to fully harness their vital contribution to sustainable development, improve human health and wellbeing, as well as foster resilience and protect the environment. (Habitat III New Urban Agenda, Draft Outcome Document for Adoption in Quito, October 2016, 10 September 2016).

Quito Declaration on Sustainable Cities and Human Settlements for All results in, among others, several points related to Inclusive Cities, mainly related to the awareness of eradicating poverty as the challenge and absolute need of sustainable development, the need for housing to prevent slum areas and informal settlement from spreading, the fulfillment of infrastructure and basic service as well as the development policy that can promote social cohesion, equality, and inclusion. The document is quoted as saying:

We recognize that eradicating poverty in all its forms and dimensions, including extreme poverty, is the greatest global challenge and an indispensable requirement for sustainable development. We also recognize that the growing inequality and the persistence of multiple forms and dimensions of poverty, including the rising number of slum and informal settlement dwellers, is affecting both developed and developing countries, and that the spatial organization, accessibility, and design of urban space, as well as infrastructure and basic service provision, together with development policies, can promote or hinder social cohesion, equality, and inclusion. (Habitat III New Urban Agenda, Draft Outcome Document for Adoption in Quito, October 2016, 10 September 2016)

It seems that the need for housing has been the emphasis and commitment, as this is revealed by promoting the national, subnational, and local housing policies that support the 
fulfillment of adequate housing for all components, mainly for homeless people, susceptible groups of people, low-income groups of people, and groups of people with disabilities. The document is quoted as saying:

We commit to promote national, subnational, and local housing policies that support the progressive realization of the right to adequate housing for all as a component of the right to an adequate standard of living that address all forms of discrimination and violence, prevent arbitrary forced evictions, and that focus on the needs of the homeless, persons in vulnerable situations, low income groups, and persons with disabilities, while enabling participation and engagement of communities and relevant stakeholders, in the planning and implementation of these policies including supporting the social production of habitat, according to national legislations and standards. (Habitat III New Urban Agenda, Draft Outcome Document for Adoption in Quito, October 2016, 10 September 2016).

In addition, there is also a commitment to the urban and rural development, response to gender issues, and empowerment for all individuals and communities as well, as stated in the document that is quoted as saying:

We commit to urban and rural development that is people centered, protects the planet, and is age and gender responsive, and to the realization of all human rights and fundamental freedoms, facilitating living together, ending all forms of discrimination and violence, and empowering all individuals and communities, while enabling their full and meaningful participation. We further commit to promoting culture and respect for diversity, and equality as key elements in the humanization of our cities and human settlements. (Habitat III New Urban Agenda, Draft Outcome Document for Adoption in Quito, October 2016, 10 September 2016)

Attention is also paid to the commitment to promoting a just and affordable access for physical and basic social infrastructures sustainable for all, without any discrimination. In addition to the need for housing, there are also other basic needs, such as adequate drinking water, sanitation and waste sewage, health, education, information and communication technology. Such services are considered being responsive to the rights and needs of, among others, women, children and teenagers, parents, the disabled, local community, and other susceptible groups of people. The document is quoted as saying:

We commit to promote equitable and affordable access to sustainable basic physical and social infrastructure for all, without discrimination, including affordable serviced land, housing, modern and renewable energy, safe drinking water and sanitation, safe, nutritious and adequate food, waste disposal, sustainable mobility, healthcare and family planning, education, culture, and information and communication technologies. We further commit to ensure that these services are responsive to the rights and needs of women, children and youth, older persons and persons with disabilities, migrants, indigenous peoples and local communities as appropriate, and others that are in vulnerable situations. (Habitat III New Urban Agenda, Draft Outcome Document for Adoption in Quito, October 2016, 10 September 2016).

The commitment is also forwarded to promoting the right steps in cities and human settlements facilitating access for the disabled, in connection with the physical environment of cities, mainly the public spaces, public transportation, housing, education and health facilities, public information and communication, including information and communication technology. This is stated in the document that is quoted as saying:

We commit to promote appropriate measures in cities and human settlements that facilitate access for persons with disabilities, on an equal basis with others, to the physical environment of cities, in particular to public spaces, public transport, housing, education and health facilities, to public information and communication, including information and communications technologies and systems, and to other facilities and services open or provided to the public, both in urban and rural areas. (Habitat III New Urban Agenda, Draft Outcome Document for Adoption in Quito, October 2016, 10 September 2016)

In addition, the commitment is also directed to promoting safe, inclusive, accessible, and green spaces with high quality. They include roads, sidewalks, bicycle lanes, seashore areas, gardens, and parks for social interaction as it is stated in the document that is quoted as saying:

We commit to promote safe, inclusive, accessible, green, and quality public spaces, including streets, sidewalks, and cycling lanes, squares, waterfront areas, gardens, and parks that are multi-functional areas for social interaction and inclusion, human health and well being, economic exchange, and cultural expression and dialogue among a wide diversity of people and cultures, and which are designed and managed to ensure human development, to build peaceful, inclusive, and participatory societies, as well as to promote living together, connectivity, and social inclusion. (Habitat III New Urban Agenda, Draft Outcome Document for Adoption in Quito, October 2016, 10 September 2016).

Promoting a safe, healthy, and inclusive environment in cities and human settlements for all to live in, work, and participate in urban life without fears of violence and intimidation has also become another commitment. This is taken into consideration that women and female children, children and teenagers, and people who are in a susceptible situation are often easy to be affected, as it is stated in the document that is quoted as saying: 
We commit to promote a safe, healthy, inclusive, and secure environment in cities and human settlements for all to live, work, and participate in urban life without fear of violence and intimidation, taking into consideration that women and girls, and children and youth, and persons in vulnerable situations are often particularly affected. We will also work towards the elimination of harmful practices against women and girls, including child, early and forced marriage and female genital mutilation. (Habitat III New Urban Agenda, Draft Outcome Document for Adoption in Quito, October 2016, 10 September 2016)

\section{B. Inclusive Cities}

The Key Drivers for developing inclusive cities are, among others, 1) Establishing Political Commitment to Inclusive Urbanization and 2) Establishing the Pathway to Inclusive Cities that consist of Participation and social innovation in planning, implementation and evaluation; Realizing the rights of all to universal access to quality basic services;3).Spatial planning for inclusion. (Habitat III Issue Papers 1 - Inclusive Cities). The following are several key points related to Inclusive Cities that are cited from Habitat III Issue Papers 1:

The role of state authorities is clear when it comes to ensuring access, affordability and adequacy of services to all in cities. Equal access of all to employment, education, adequate housing, health services, justice, water, sanitation, electricity and transports, all contribute to inclusiveness and social cohesion. Despite obligations toward all inhabitants to uphold their rights and the evident benefits of having more inclusive cities, a wide range of factors drive exclusion in cities. (Habitat III Issue Papers 1 - Inclusive Cities).

Special emphasis should be placed on increasing women's, young people's and older person's participation in democratic life and decision making at all levels. Gender equality perspectives should, for example, be mainstreamed into all decisions around budgeting, infrastructure investments, and land-use and development planning. (Habitat III Issue Papers 1 Inclusive Cities).

Promoting universal, age and gender responsive access to quality basic services: An urban age and gender responsive development model with adequate policies and institutional frameworks, for promoting universal access to urban basic services, such as sustainable and affordable housing, health including sexual and reproductive health, nutritious food, water and sanitation, education and training facilities, including lifelong learning and vocational education, and basic income security, especially for urban dwellers living in poverty and those experiencing discrimination, is another lever of change. Such services should be available and accessible to everyone, and meet certain minimum quality standards as established by international human rights law. (Habitat III Issue Papers 1 Inclusive Cities).
The discussion on inclusive cities becomes the agenda of the discussion that is held just before the implementation of PrepCom 3 habitat III. The result of the discussion is, among others, the statement that it is hard to apply what is discussed in the United Nations. The problem does not have anything to do with geographical and spatial engineering. Instead, it has something to do with social and economic problem so that social aspects need to be empowered. It is free for the power around elite groups (the authorities) to make use of spaces. It is hard to apply inclusive urban agenda when the problems are not broken down. Not all cities are capable of providing infrastructures as what is suggested by the United Nations. Developing infrastructure is often not accompanied with improving utility capacity. It is necessary to make a movement of using infrastructure in a correct way. To change from being exclusive to being inclusive is a challenge in city development.

The conclusions taken from the discussion at that forum are; (1) Indonesia must prepare itself to contribute in the New Urban Agenda, where each city is able to take part in making the achievement at its best practices, (2) It is important to pay attention to the social aspects of developing inclusive cities, (3) Toward an inclusive city, urban development needs to take inclusive groups (the poor, children, the elderly, the disabled, women) into consideration. City development needs to be supported by the regulations of plan products, (4) It is necessary to intensify the role of the youth as a group that can contribute to and participate in development.

The discussion on inclusive city becomes more important considering that the poor have so far been marginalized for the sake of a bigger interest. They are still susceptible to being driven away and removed. In any case, a city needs to be developed in a good way by accommodating the voice of all parties, including the poor. Not only does an inclusive city accommodate aspiration from its community, but it also involves them in development. Inclusion is a key point in city development. A city can grow well if it is able to involve all its subjects. The poor and middle class are usually the majority people of a city. They can make significant contribution to city development. In this case, they can contribute to city development by expressing their ideas.

An inclusive city is the one that is able to provide public facilities of which the marginalized groups of people like the disabled, the elderly, children, women, etc. can make use. An example of this is that the construction of road and its supporting facilities must be able to be accessed by those groups of people. Sidewalk, for example, is a place where pedestrians can take a walk without any obstruction and that it needs to be well constructed to facilitate and accommodate the disabled, children, and the elderly as well. The same case is roads. It is important to provide signs that are very useful for the disabled. The blind, for example, can cross the street safely and comfortably without any fear at the designated place, popularly called zebra cross. The 
construction of a building also pays attention to the need of inclusive groups. For example, it is necessary to provide ways specially designed for someone with a wheelchair to enter the building. The same case is a restroom that is particularly planned for them.

\section{The Implementation of Inclusive City Development in Yogyakarta City}

The discussion on inclusive city before PrepCom 3 habitat III is held in relation to the city of Yogyakarta shows that the development in the city is just about to pay attention to five groups of marginalized people, i.e. the poor, women, children, the elderly, and the disabled. In relation to the vision of city development as an education city, toward the inclusive city of Yogyakarta it is important to apply inclusive education, namely access for all, education for all, and responses to diversity. There should be a movement enforcing the value of 4 (four) pillars, i.e. discipline, self-reliance, care, and togetherness. Meanwhile, in relation to health the city government has provided Jamkesus and Jamkesda for the poor. For housing, the existing houses are the ones that are properly built to live in. Furthermore, in relation to human resources, there have been jobs available for the disabled to do. From the point of poverty eradication, inclusion can be exemplified compiling poverty indicators to determine local criteria for the involvement of community. From the protection and fulfillment for the right of the disabled, inclusion can be exemplified by caring mainly for the health of the female disabled. The community participation in Musrenbang through the survey of sharing for community aspiration in the city of Yogyakarta has given opportunities to all groups of community to participate in the process of development planning. At this moment, musrenbang for children and women has been developed in the city of Yogyakarta.

Furthermore, the following is the implementation of inclusive city development in the city of Yogyakarta as the description of how it is implemented in one of the big cities in Indonesia. The description is taken from the document of final report of RPJMD of the city of Yogyakarta years 2017 - 2021.

The development in the city of Yogyakarta does not only focus on the one of physical environment but also on social environment. This is a response in facing the fact that there is still discrimination that the disabled, children, women, the elderly, and the poor are experiencing. They are a group of people who are often marginalized and do not benefit fully the results of development. Through inclusive city development, public services need to be improved in all sectors and provided for all social strata, including those who are in need for special service like the disabled with different abilities. With this inclusive concept, it is expected that all people living and doing activities in the environments of family, school, community feel secure and comfortable to accept their rights and do their obligations without any discrimination, particularly those belonging to five groups of people (children, women, the elderly, the poor and the disabled).

A city with high quality of education is stated in the vision of the city of Yogyakarta. This can be the basis of inclusive city development in the sector of inclusive education, this is the educational system that encourages creativity by giving access to all people in one system that covers school, non-formal / informal program, education in family and society and makes all parties of people involve themselves fully. This constitutes a process and purpose that describes the qualities or characteristics of education for all. The method of inclusive education is the one that improves the system of formal, non-formal / informal education by responding diversity as well as identifying obstacles that individuals and groups of children face. However, inclusive education does not only have anything to do with method and system, but it also deals with basic values and beliefs about the importance of appreciating and respecting differences, no discrimination, and collaborating with others to create this world a more just place to live in, particularly for the five groups of people as mentioned above. Inclusive development does not only focus on economic aspect, but also on giving access to all social strata in benefitting the results of development, including infrastructure and basic services.

The Regional Regulation of the city of Yogyakarta No. 4 year 2012, in relation to inclusive development, states the protection and fulfillment of the rights of the disabled, i.e. 9 (nine) points of rights namely education, health, job opportunity, social, cultural art and sports, law, politics, disaster tackling, and settlement. In the city of Yogyakarta, there are 2.444 disabled people. In the city of Yogyakarta, the number of disabled persons who are listed in the stipulation of participants for insurance in 2014 is 1.861 persons. The fact that most disabled persons in the city of Yogyakarta are on the list indicates the economic susceptibility of the most disabled persons. That number constitutes $\pm 1 \%$ of the population of the city of Yogyakarta. City services accessible and friendly to the disabled become the indicators of the success for the realization of inclusive city.

\section{CONCLUSION}

Inclusive city development has currently become a need, considering that the groups of marginalized people are also becoming the center of attention in urban development, particularly those belonging to five groups of people i.e. children, women, the elderly, the poor and the disabled. Therefore, the result of development is not only intended to exclusive groups of people, but it should also be intended for inclusive groups of people. Infrastructure and urban basic services need to be built and improved by also considering the inclusive groups of people. To realize the success of inclusive city, it takes commitment, coordination, and accessibility. 


\section{REFERENCES}

[1] Bappeda Kota Yogyakarta, 2016, "Laporan Akhir RPJMD Kota Yogyakarta 2017-2021"

[2] Gupta, Joyeeta., dan Vegelin, Courtney, 2016, "Sustainable development goals and inclusive development". Jurnal Int Environ Agreement, Volume 16, Hal 433-448

[3] Habitat III Zero Draft of The New Urban Agenda 06 May 2016

[4] Habitat III Draft New Urban Agenda 28 July 2016

[5] Habitat III New Urban Agenda Draft Outcome Document for Adoption In Quito, October 2016. 10 September 2016

[6] Habitat III Issue Papers 1 - Inclusive Cities. 26 to 29 May 2015. 